\title{
EVALUATION OF THE MENTAL FORAMEN POSITION USING DIGITAL PANORAMIC RADIOGRAPHS IN SELECTED COSTAL POPULATION OF ANDHRA PRADESH
}

\section{T. Sravani ${ }^{1}$, M. Venkateswarrao ${ }^{* 2}$, M. Rakesh kumar ${ }^{3}$, C.K. Lakshmi Devi ${ }^{4}$}

${ }^{1}$ Assistant Professor,Department of Anatomy,Government Medical College (RIMS), Kadapa, Andhra Pradesh, India.

${ }^{* 2}$ Assistant Professor,Department of Anatomy,Narayana Medical college,Nellore, Andhra Pradesh, India.

${ }^{3}$ Professor,Department of Oral medicine and Radiology,Narayana Dental College,Nellore, Andhra Pradesh, India.

${ }^{4}$ Professor and HOD,ACSR GMC,Nellore, Andhra Pradesh, India.

\section{ABSTRACT}

Introduction: Mental foramen is defined as the funnel-like opening in the lateral surface of the mandible at the terminus of the mental canal. The mental foramen is the termination of the mandibular canal in the mandible, transmits the inferior alveolar nerve and vessels. Accurate position of the mental foramen would help surgeons in achieving successful anaesthesia to the terminal branches of the inferior alveolar nerve. The aim of the study was to evaluate the most common radiographic position of mental foramen in costal population of Andhra Pradesh.

Materials and methods: A total of 250digital panoramic radiographs were collected between age of 16 and $60 y$ rs, which fulfil the inclusion criteria.

Results: We observed that, in $40.4 \%$ of individuals mental foramen was in line with second premolar (position 4) followed by $27.8 \%$ between the first and second premolars (position 3), least common is position 1 in $4 \%$ of the population. We also observed the mental foramen position to vary with gender and on right and left sides.

Conclusion: The most common position of mental foramen is position 4. Gender and right and left side variations were also observed in our study. surgeons should carefully identity mental foramen position in achieving successful anaesthesia to the terminal branches of the inferior alveolar nervebefore going for the surgery of the lower jaw and floor of the mouth.

KEY WORDS: Mental foramen, panoramic radiograph, mandible.

Address for Correspondence: Dr. M. Venkateswarrao,Assistant Professor,Department of Anatomy, Narayana Medical college,Nellore, Andhra Pradesh, India.E-Mail: mvraosj@gmail.com

\section{Quick Response code}

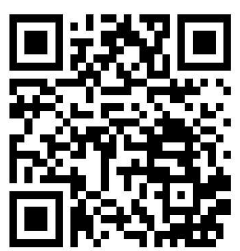

DOI: $10.16965 /$ ijar.2019.197 Journal Information

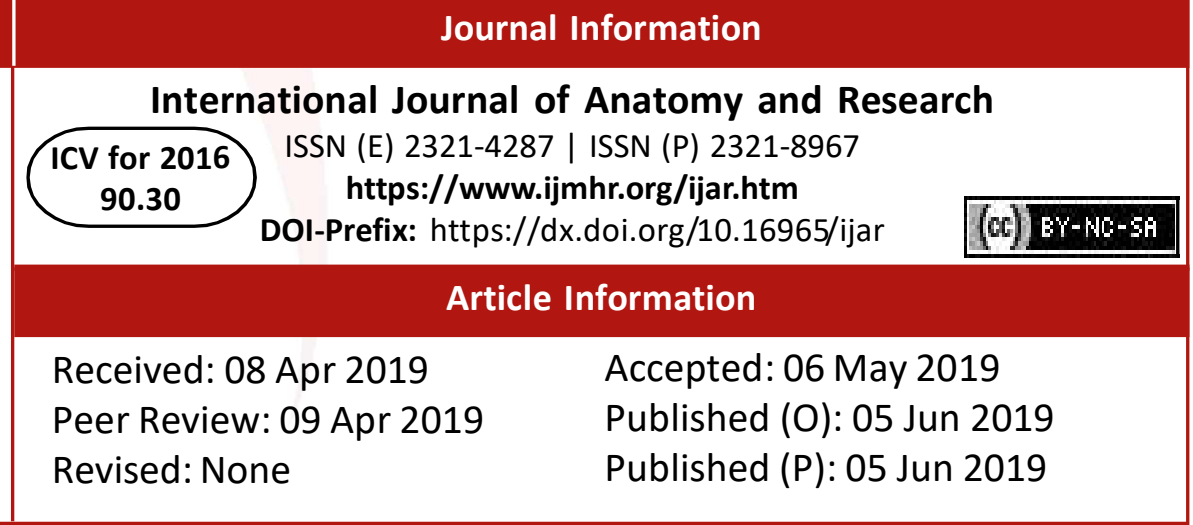

\section{INTRODUCTION}

Mental foramen (MF) is defined as the funnellike opening in the lateral surface of the mandible at the terminus of the mental canal.
The mental foreman is the termination of the mandibular canal in the mandible, transmits the inferior alveolar nerve and vessels. These nerve and vessels are responsible for blood supply 
and innervation of the lower lip, the buccal vestibule, the gingiva mesial to the mandibular first molar, and mandibular incisors, canines, and premolars[1].Identification of correct position of the MF is essential for the surgeons during local anaesthesia and various operative procedures of the anterior mandible. Unseemly spotting of the MF can results in inadequate anaesthesia and damage to the mental nerve. The Complications of damaged mental nerve may result in paraesthesia, hypoesthesia, dysesthesia, and anaesthesia of the teeth, lower lip, andor surrounding skin and mucosa[2].

MF cannot be clinically visualised or palpated and has no appreciable consistent reference anatomical landmarks. MF changes its position with age, gender, and the ethnicity[3]. The age variations in the position of MF can be due to the forward growth of the mandible during development and the differential rates of bone and periosteum development[3, 4].MF can be best located by three dimensional imaging of the mandible and preoperative imaging is mandatory before commencing the surgery [4].

Three dimensional imaging like Cone Beam Computed Tomography in the present day is more expensive to be afforded by average Indian. The less expensive alternative to study the position of MF is Digital panoramic radiograph. Panoramic radiograph qualifies to measure the position of the MF in relation to the mandibular midline and other bony landmarks, long axis of adjacent teeth, and on right and left side $[4,5]$.The purpose of this study was to report the actual position of the MF on right and left sides of the mandible and gender variations if any in selected costal population of Andhra Pradesh

\section{MATERIALS AND METHODS}

Total of 250 digital panoramic radiographs were taken from the department of Oral Radiology, Narayana Dental College and hospital, Nellore, Andhra Pradesh. Patients over 16yrs of age, presence of all mandibular teeth, and optimal image characteristics (quality) on the panoramic radiographs were included in the study. Oral radiologist checks all the panoramic radiographs and only high quality panoramic radiographs were selected. Panoramic radiographs showing spaced, crowded or rotated teeth, missing mandibular canines, premolars, and molars showing radiolucent or radiopaque lesions in the mandibular canine-premolar-molar region, presence of supernumerary teeth in the mandibular canine-premolar-molar regions, and radiographic artefacts were excluded from the study. All the radiographs were taken using Promax software (Planmeca, Finland) with standard exposure factors (70Kv, 8Ma, and 15.8 sec). The position of MF was recorded by two independent oral radiologists according to Anshumen et al.[3], as follows:

Position 1: situated anterior to the first premolar

Position 2: In line with the first premolar

Position 3: Between first and second premolars

Position 4: In line with second premolar

Position5: Between the second premolar and first molar

Position 6: In line with the mesio-buccal root of first molar.

The position of the mental foramen was noted by drawing an imaginary lines parallel to the long axis of the mandibular canine, premolars, and molars. Inter observer variabilities were resolved with mutual consensus. The position of the mental foramen on right and left side and age were recorded on premade form and percentages were calculated. The data was analysed using SPSS software version 16.

\section{RESULTS}

A total of 250digital panoramic radiographs were analysed between age of 16 and 60yrs, which fulfil the inclusion criteria. We observed that, in $41.2 \%$ right and $39.6 \%$ left sidesof individuals mental foramen was in line with second premolar (position 4) (Fig;4) followed by $24 \%$ right and $31.6 \%$ left sidesbetween the first and second premolars (position 3) (Fig; 3), 18.4\% right and $16 \%$ left sidesbetween second premolar and first molar region (position 5) (Fig; 5), 8.4\% right and $4 \%$ left sides in line with mesio-buccal root of first molar (position 6) (Fig; 6), 3.9\% right and $5.6 \%$ left sidesin line with first premolar (position 2) (Fig;2), and $4.8 \%$ right and $3.9 \%$ left sides situated anterior to first premolar (position 1) (Fig;1). 
Fig. 1: Mental foramen in position 1.

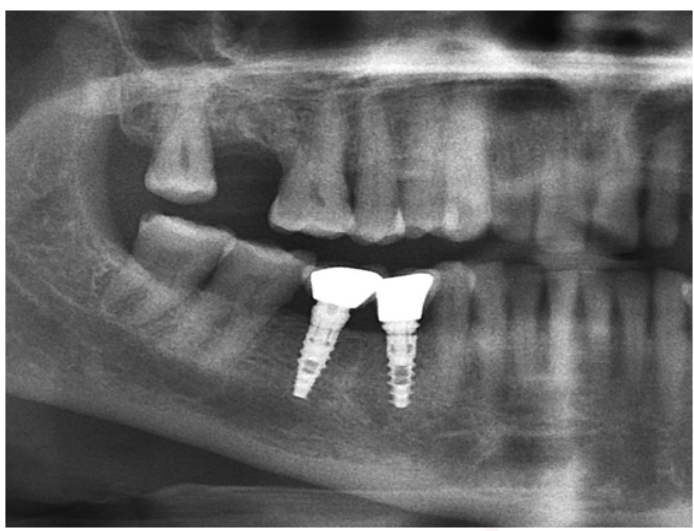

Fig. 2:Mental foramen in Position - 2.

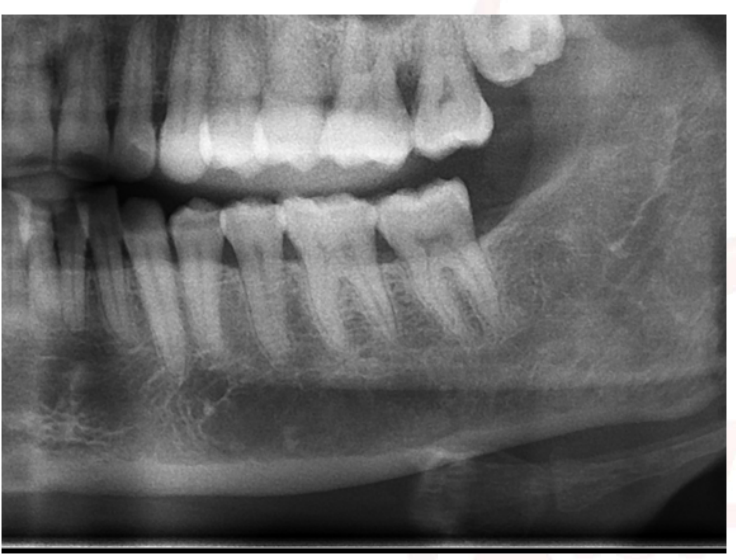

Fig. 3: Mental foramen in Postion - 3.

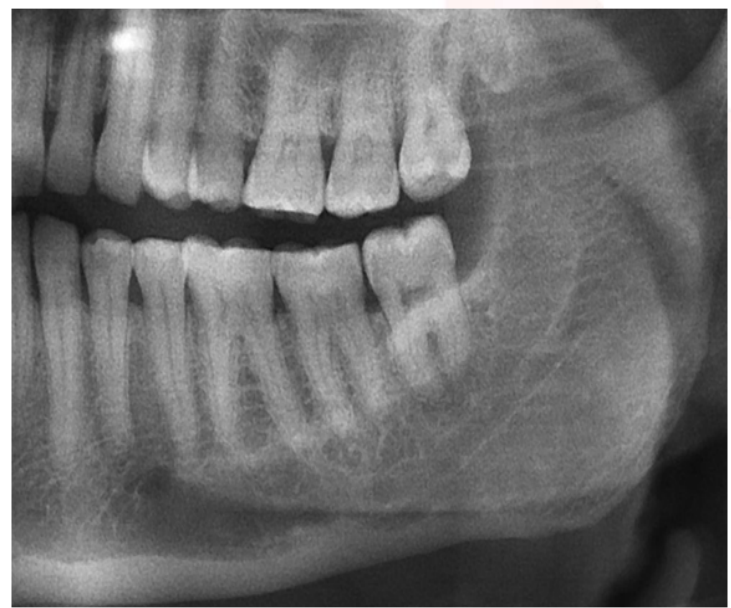

Fig. 4:Mental foramen in Position - 4.

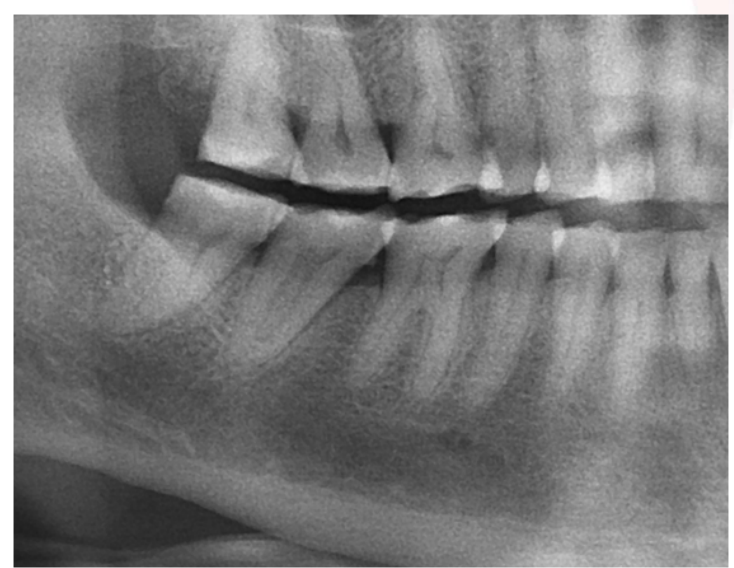

Fig. 5: Mental foramen in Position - 5.

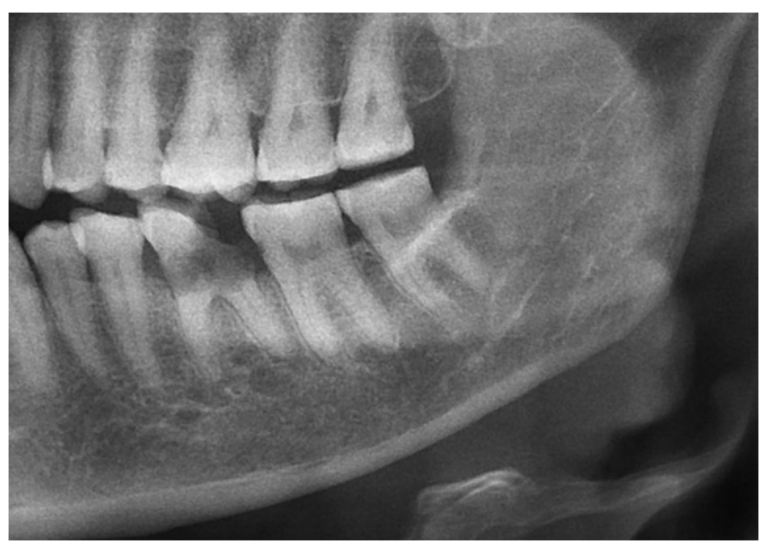

Fig. 6: Mental foramen in Postion - 6.

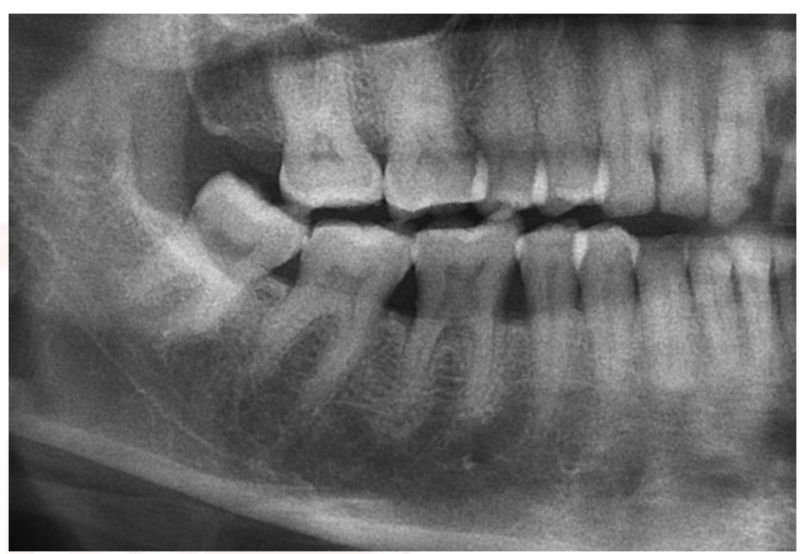

There is no statistically significance of mental foramen position between right and left side $(\mathrm{p}=0.929)$. (Table 1)

Present studyshowed there is no statistically significance of mental foramen position between right and left side among males $(p=0.392)$ and females $(p=0.272)$. the observations in males are $23.2 \%$ right side and $24.8 \%$ left side of individuals mental foramen was in line with second premolar (position 4) followed by $11.2 \%$ right side and $9.2 \%$ left side between second premolar and first molar region (position 5), $8 \%$ right side and $10.8 \%$ left side between the first and second premolars (position 3 ), $2.8 \%$ right side and $1.2 \%$ left side in line with mesio-buccal root of first molar (position 6), $2 \%$ right side and $2.8 \%$ left side in line with first premolar (position 2), and $2.8 \%$ right side and $1.2 \%$ left side situated anterior to first premolar (position 1).In females, $18 \%$ right side and $14.8 \%$ left side of individuals mental foramen was in line with second premolar (position 4) followed by $16 \%$ right side and $20.8 \%$ left side between the first and second premolars (position 3 ), $7.2 \%$ right side and $6.2 \%$ left side between second premolar and first molar region 
Table 1:Mental foramen position on right and left side of the mandible.

Chi square value $=9.4345$, $p=0.929$

\begin{tabular}{|l|c|c|c|}
\hline \multicolumn{1}{|c|}{ Location } & Left & Right & Total \\
\hline Anterior to $1^{\text {st }}$ premolar region & $08(3.9 \%)$ & $12(4.8 \%)$ & $20(4 \%)$ \\
\hline $1^{\text {st }}$ premolar region & $14(5.6 \%)$ & $08(3.9 \%)$ & $22(4.4 \%)$ \\
\hline Between $1^{\text {st }} \& 2^{\text {nd }}$ premolar region & $79(31.6 \%)$ & $60(24.0 \%)$ & $139(27.8 \%)$ \\
\hline $2^{\text {nd }}$ premolar region & $99(39.6 \%)$ & $103(41.2 \%)$ & $202(40.4 \%)$ \\
\hline Between $2^{\text {nd }}$ premolar $\& 1^{\text {st }}$ molar region & $40(16.0 \%)$ & $46(18.4 \%)$ & $86(17.2 \%)$ \\
\hline $1^{\text {st }}$ molar region & $10(4.0 \%)$ & $21(8.4 \%)$ & $31(6.2 \%)$ \\
\hline
\end{tabular}

Table 2:Mental foramen position in males and females.

\begin{tabular}{|l|c|c|c|c|}
\hline \multirow{2}{*}{ Location } & \multicolumn{2}{c|}{ Male } & \multicolumn{2}{c|}{ Female } \\
\cline { 2 - 5 } & Left & Right & Left & Right \\
\hline Anterior to $1^{\text {st }}$ premolar region & $3(1.2 \%)$ & $7(2.8 \%)$ & $5(2 \%)$ & $5(2 \%)$ \\
\hline $1^{\text {st }}$ premolar region & $7(2.8 \%)$ & $5(2 \%)$ & $7(2.8 \%)$ & $3(1.2 \%)$ \\
\hline${\text { Between } 1^{\text {st }} \& 2^{\text {nd }} \text { premolar region }}^{\text {nd }}$ premolar region & $27(10.8 \%)$ & $20(8 \%)$ & $52(20.8 \%)$ & $40(16 \%)$ \\
\hline $2^{\text {Between } 2^{\text {nd }}}$ premolar \& $1^{\text {st }}$ molar region & $23(9.2 \%)$ & $28(11.2 \%)$ & $17(6.8 \%)$ & $18(7.2 \%)$ \\
\hline $1^{\text {st }}$ molar region & $3(1.2 \%)$ & $7(2.8 \%)$ & $7(2.8 \%)$ & $14(5.6 \%)$ \\
\hline
\end{tabular}

In males, Chi square value $=5.1994, p=0.392$ In females, Chi square value $=6.3076, p=0.272$

(position 5),5.6\% right side and $2.8 \%$ left side in line with mesio-buccal root of first molar (position 6 ), $1.2 \%$ right side and $2.8 \%$ left side in line with first premolar (position 2), and $2 \%$ each onright and left sides situated anterior to first premolar (position 1).(Table 2)

\section{DISCUSSION}

Knowledge about the exact position of the MF is of great clinical importance. It would aid in giving the local anaesthesia more accurately there by providing better anaesthesia and preventing injury to mental neuro vascular bundle. Due to inconsistent anatomical land marks and inability to palpate, Oral Panoramic radiographs are widely used to study the location of the MF. According to our study in $40 \%$ of the individuals, MF was present in line with second premolar (position 4)followed by $27.8 \%$ between the first and second premolars (position 3). Our findings are almost similar with the findings by many Indian studies $[6,7]$ and not analogous with western study [4]. Mental foramen position varies with different population is well understood.

Giving mental nerve block at apex of second premolar or between apex of first and second premolars could anesthetizes the nerve in $75 \%$ of costal population of Andhra Pradesh. Studies done in UK and Iranian populationfound mental foramen position between first and second premolars in contrast to Indian population $[1,4]$.

Int J Anat Res 2019, 7(2.3):6652-56. ISSN 2321-4287
These variations in the position may be because of ethnic and racial discrimination of the selected population.Weobserved position 1 and 6 are rare in the present study, which is in accordance with the studies done by many authors $[1,6,7]$.

The mental foramen position found to be almost symmetrical between right and left sides of the mandible and almost in accordance with previous studies. $[1,4,6]$. Studies showed age alters the mental foramen position in anteriorposterior and superior-inferior directions. Increased age positions the mental foramen more posterior location. Mental foramen is close to superior margin of the mandible before tooth eruption, between superior and inferior margins during tooth eruption, close to inferior margin in adults, and near to superior marginas ridge resorbs during old age [1, 7].

The present retrospective cross sectional study is with limitation couldn't assess the age altered mental foramen positions as sample included with predominant population with permanent dentition. No significant mental foramen position varied between right and left sides of the mandible among males and females, which is in agreement with previous studies [8].

Morphological position and range of mental foramen location is very important when administrating local anaesthesia and performing surgeries. Nerve block at the range from apex 
of second premolar to between apex of first and second premolars could be given in costal population of Andhra Pradesh irrespective of gender and right or left side for effective anaesthesia. The limitations include small sample size with permanent dentition, and panoramic radiographs may obscured mental foramen. Studies need to be done with large sample size with mixed dentition, three dimensional imaging, and multicentre studies within different population may give accurate position of mental foramen.

\section{Conflicts of Interests: None}

\section{REFERENCES}

[1]. Al-Shayyab MH, Alsoleihat F, Dar-odeh NS, Ryalt S, Baqin ZH. Foramen mental I: radiographic study of the anterior-posterior position and shape in Iraqi population. Int. J. Morphol.2015;33:149-157

[2]. Suragimath A, Suragimath G, Murlasiddiah SK. Radiogaphic location of mental foramen in a randomly selected population of Maharashtra. J Indian Acad Oral Med Radiol. 2016; 28:11-16

[3]. Babshet M, Sandeep R, Burde K, Nandimath K. Evaluation of the position of mental foramen and its correlation with age in selected Indian population, using digital panoramic radiograph. International Journal of Dental Sciences and Research. 2015;3:87-91
[4]. Currie CC, Meechan JG, Whitworth JM, Carr A, Corbett IP. Determination of the mental foramen position in dental radiographs in 18-30 year olds. DentomaxillofacRadiol. 2016; 45:20150195.

[5]. Moni Takur, Vinay Kumar Reddy K, Sivaranjini Y, Shaikh Khaja. Gender determination by mental foramen and height of the body of the mandible in dentulous patients. J. Indian Acad. Forensic Med. 2104;36;1

[6]. SarithaMaloth, Shrinivas TR, Padmashree S, Pramod Krishna B, Priya M. Study on the position and symmetry of the mental foramen on panoramic radiographs in Indian population. Journal of international medicine and Dentistry. 2015;2:147-155

[7]. Mohamed A, Nataraj K, Mathew VB, Varma B, Mohamed S, Valappila NJ, Meena AS.Location of mental foramen using digital panoramic Radiography. J Forensic Dent Sci. 2016; 8:79-82.

[8]. Gupta V, Pitti P, Sholapurkar A. Panoramic radiographic study of mentalforamen in selected dravidians of south Indian population: A hospital basedstudy. J ClinExp Dent. 2015; 7:e451-6.

How to cite this article:

T. Sravani,M. Venkateswarrao,M. Rakesh kumar, C.K. Lakshmi Devi. EVALUATION OF THE MENTAL FORAMEN POSITION USING DIGITAL PANORAMIC RADIOGRAPHS IN SELECTED COSTAL POPULATION OF ANDHRA PRADESH. Int J Anat Res 2019;7(2.3):6652-6656. DOI: 10.16965/ ijar.2019.197 